\title{
Lexico-Semantic Features of Pakistani English Newspapers: A Corpus-Based Approach
}

\author{
Sartaj Fakhar Jilani ${ }^{1} \&$ Behzad Anwar ${ }^{2}$ \\ ${ }^{1}$ Department of English, Govt. Degree College (W), College Road, Gujranwala, Pakistan \\ ${ }^{2}$ Department of English, University of Gujrat, Gujrat, Pakistan \\ Correspondence: Sartaj Fakhar Jilani, Department of English, Govt. Degree College (W), College Road, \\ Gujranwala, Pakistan. E-mail: Sartaj_bakht@yahoo.com
}

\author{
Received: January 8, 2018 Accepted: February 8, 2018 Online Published: March 17, 2018 \\ doi:10.5539/ijel.v8n4p50 URL: https://doi.org/10.5539/ijel.v8n4p50
}

\begin{abstract}
Lexico-semantic variation with its socio-cultural significance, genuinely instilled in the tint of adaptation as well as innovation, has prompted many researchers and linguists to explore profoundly within the prolific soil of Pakistani English, while formulating its mark within the sphere of "New Englishes". This "norm-developing" variety traces the accelerating concern in the momentum of diffusion of "World Englishes", and consequently, adding to the evolution and development of English in non-native-contexts with its deep enriching essence. The principal goal of the present research work is to investigate lexico-semantic variation in Pakistani English newspapers along with the functional outcomes within the vibrant mould of perceptions based on context-dependent Pakistani socio-cultural scenarios in the light of Moag's model based on "New Englishes", Boas' Cultural Relativism, Kachru's Nativization and Acculturation with the conception of "Outer Circle" mainly connected to institutionalized Second Varieties of English. The study further analyzes two major lexico-semantic categories based on the corpus derived from two leading Pakistani English Newspapers. This corpus-based study took out the sample texts with their usual lengths, purposively chosen, from the real life. Findings of the study highlight that lexico-semantic categories in Pakistani English Newspapers are infused within the local aroma while having a diversity of colours of usage and elucidations in multifaceted functional settings of Pakistan. The study broadens the horizons while opening a wide range of opportunities for the researchers in grammar, lexicon, semantics, pragmatics etc. by means of construction and extension of corpora and drawing comparison with the other varieties of English.
\end{abstract}

Keywords: variation in New Englishes, lexico-semantic change, Newspaper corpus

\section{Introduction}

Language, being the principal articulator of socio-cultural conceptualizations, encompasses the psychometrics of the society entwined in attitudinal modifications, social insights, individual and group interactional patterns which further comprise the intrinsic component of language usage within the society. Consequently, such internally-motivated communicative exchanges determine the lexico-semantic norms, deeply embedded within the underlying cultural moves while serving as the linguistic icons as well as the markers of the unique social identity. In this context, the newly emerging varieties of English, i.e., "New Englishes", "Institutionalized Second Language Varieties", "International Englishes" etc. are spreading their wings on the international horizon owing to the unparalleled broadening of the English language around the world. This diversity of usage in multicultural frameworks is brought to light by Ethnologue (2017) which reveals that the overall figure of users of English in all countries has escalated up to 983,522,920 (as L1: 371,959,910; as L2: 611,563,010), which virtually envelops a quarter of the globe's populace, who can understand it and are at least, in essence, dexterous users of both spoken or written English. This computation emphasizes the fact that the number of non-native speakers of English outshines the number of native speakers by a stupendous ratio of 3 to 1 . It is interesting to note that the number of non-native English speakers is approximately double the number of native English speakers, with the number of non-native speakers recurrently mounting. Thus, such pluralizationin the form of "New Englishes" "have a long history of acculturation in new cultural and geographical contexts; they have a large range of functions in the local educational, administrative and legal systems" (Kachru, 1986 as cited in Balasubramanian, 2016, p. 91). In this perspective, nativization of the English Language by the local users takes 
place which establishes the development and expansion of English within the new socio-cultural milieus in terms of variation and novelty while adding a distinctively exclusive flavor entirely different from British and American varieties of English. Surely, "English now has multicultural identities" (Kachru, 1985, p. 357).

In this regard, "Pakistani English" as an independent "norm-developing" variety emerges as a sub variety of South Asian Englishes which, in fact, shares various features of Asian and South Asian Englishes in broader spectrum. Kachru \& Nelson (2006) deem that "“local usages", elements of Pakistani English (in the World Englishes perspective) are of legitimate interest" (p. 128). In this outlook, Baumgardner (1987) holds the view that Pakistani English is a nativized, institutionalized variety of English profoundly entrenched within the local and socio-cultural norms. (p. 242)Thus, Pakistani English refashioned in this way mirrors the manifestation of nationalistic as well as communicative spirit of a non-native culture where it has been transplanted and where it is cultivated within the local setting while proliferating indigenous flavors as an outcome of usage by local Pakistani users. Kachru (1986) quotes Dustoor (1968) to further accentuate this truth:

"There will always be a more or less indigenous flavor about our English. In our imagery, in our choice of words, in the nuances of meaning we put into our words, we must be expected to be different from Englishmen and Americans alike." (p. 97)

Hence, Pakistani English as a non-native variety is paving its way further towards codification.

\subsection{Research Questions}

1). What kind of Lexico-Semantic variations can be found in Pakistani English Newspapers?

2). How context-dependent scenarios influence the perceptions based on Lexico-Semantic perceptions in Pakistani context?

\subsection{Theoretical Undercurrents of the Study}

The present study is channelized by means of a range of significant theories and models such as Kachru's "Three Circles Concentric Models" (1988) specifically "The Outer circle" which is chiefly connected to Institutionalized Second Varieties of English (ESL), Pluralization of English as "Englishes" and allocation of equivalent status to every variety of English. Moreover, Moag's Model based on the developmental phases of "New Englishes" (1992), Boas' theory of Cultural Relativism (1963) and Kachru's concepts of "Nativization" and "Acculturation" (1992) also form the underlying basis for the present study. The researcher aimed to connect these theories and models with the subject matter of the research to comprehend their implications in Pakistani context.

\subsection{Significance of the Study}

The outcomes of the present study are based on distinctive categories of lexico-semantic variation drawn from Pakistani English Newspapers in the light of diverse cultural and contextual factors. It opens up new possibilities regarding the employment of corpora for systematic classification of other lexico-semantic categories like proverbs, metaphors, similes and a wide range of linguistic analyses in the field of grammar, phonology, morphology, semantics and even discourse in broader spectrum. The present research will also prompt the researchers to build corpora based on different genres by means of which analogous corpora can be prepared within the Pakistani variety of English and also for the comparison of Pakistani English with other native and non-native varieties of English. Moreover, the future researchers may would the dimension towards lexico-syntactic, morpho syntactic and even semantico-grammatical grounds within the texts having varying discourse patterns of Pakistani English. Therefore, this study is a useful and significant resource for sociolinguists as it highlights the sociolinguistic profile of a unique non-native variety of already transplanted English in a plurilingual and multicultural context. It is also valuable for the local as well as Indo-Aryan and South Asian language teachers, linguists and scholars, as by employing a corpus-based approach, new possibilities of investigation regarding linguistic and functional characteristics by means of lexico-semantic variations as well as innovations are opened up not only in genre of newspapers but also in the other literary genres like novels, short stories and edited works. In addition, the study will be fruitful regarding the fast and easy access to the linguistic content in the corpus of written discourse of Pakistani English on the basis of preferences while creating a sense of empowerment. Additionally, the present study is important for the language planners, as well as syllabus and curriculum designers to incorporate these lexical innovations and lexico-semantic variations in framing linguistic phenomena by adding the local colour. It also establishes a dire need of codification of these lexico-semantic items in books and dictionary of Pakistani English. On the whole, the present research work will broaden the scope of researchers because it reflects the probable modifications in the English language by putting it in the mould of linguistically fertile socio-cultural frame of Pakistani context. 


\section{Review of Related Research}

Paikedey's (1985) declaration "The native speaker is dead!" and McArthur's (1993) assertion that "there is a club of equals here" strongly implicate the conception that "ownership of the English language" is no more confined to native speakers only, rather users of the English language cross culturally become the chief proprietors of English pertaining their specific but multidimensional range of functional milieus. Such features are hallmarks of Pakistani English as well which herald the pluricentric approach in terms of diversifying sociolinguistic and literary resourcefulness. Consequently, acculturation takes place particularly regarding differing linguistic frameworks and sociolinguistic ecologies while connecting English to multicultural identities and rich cultural repertoires (Kachru, 1965; Strevens, 1992; Bamgbose et al., 1995). In this perspective, Baumgardner (1993) rightly points out that:

"English in Pakistan can be identified according to certain distinctive linguistic features of grammar, word formation, lexical variation, borrowing etc." (p. xvi)

Thus, subsistence of Pakistani English retains its value in terms of its various indexical indicators in alliance with the phonological, morphological, syntactic and discourse levels of linguistic association and further encompasses lexis and semantics in contextual constructs. These multidimensional facets of Pakistani English have been investigated by various distinguished scholars like Baumgardner (1993), Talaat (1998, 2002), Mahboob (2003, 2013), Anwar (2011), Rehman (2014), Mahmood (2012), Mahmood (2012), Uzair (2012) and Sheeraz (2014). These researchers brought to light various linguistic, social and cultural aspects in general but no study has yet been carried out to probe and tackle specifically the lexico-semantic versions in Pakistani English newspapers by means of corpus-based method. The findings of aforementioned scholars contribute a lot in promoting the Pakistani variety of English while underlining the features on the whole along with cultural and ideological representations in general and lexico-grammatical features as well as forms and functions in particular. Though, phonological, morphological and syntactic variations have been explored by the aforesaid researchers as well as many other Pakistani scholars, however, lexico-semantic features in the broader context are unexplored yet. Therefore, lexico-semantic variation paved the foundation that language in Pakistan is fashioned by range, diversity and function in Pakistani society. In this regard Leech (1974, p. 49) presents a good range of functions of language manipulated in a society by means of a diagram:

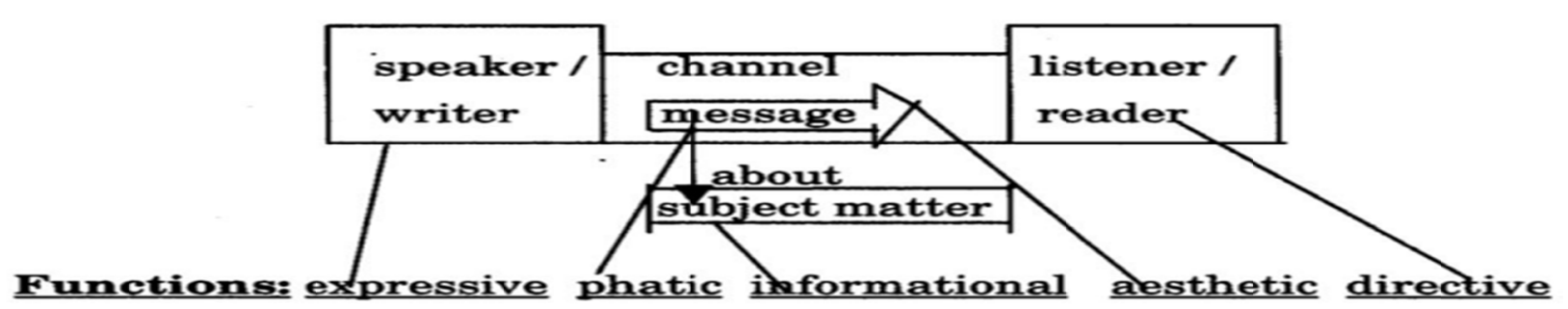

Figure. Functions of language in the society (Adapted from Leech, 1974, p. 49)

All the aforementioned functions herald the lexico-semantic range of Pakistani English demarcated by means of the contextual components on the cline of intelligibility interconnecting the dynamic socio-cultural and linguistic features. Rao's (1938) assertion, as an Indian writer seems quite significant here when he states:

"One has to convey in a language that is not one's own the spirit that is one's own. One has to convey the various shades and omissions of a certain thought-movement that looks maltreated in an alien language... We are all instinctively bilingual, many of us writing in our own language and in English. We cannot write like the English. Our method of expression therefore has to be a dialect which will someday prove to be as distinctive and colorful as the Irish and American. Time alone will justify it" (pp. 9-10).

Rao's affirmation clearly signifies the nature of lexico-semantic tendencies in Pakistani perspective which are also deeply imbued within the intellectual make-up of the users of Pakistani English particularly coupled with "Nativization" and "Acculturation". Consequently, Lexico-Semantic variation serves as the chief requisites in the multilingual community of Pakistan within its socio-cultural locale.

So, Lexico-Semantics, established by Katz \& Fodor (1963), broke new grounds owing to the repercussions of lexical items supported by means of their componential characteristics, i.e., the componential breakdown, which 
is an outcome of lexical configurations. It further refers to the association between the lexicon of a language (i.e., its root-words and word-stems) and a series of prospective semantic alignments shaped by the human mind. Every language (and predominantly every language family) segregates the world in a special way in terms of notions specifically wrapped into words and how the connotations of those words replicate the reality around us. Hence, Lexical Semantics is correlated with words and their meanings. Fromkin, Rockman, \& Hyams (2007) maintains in this regard that the meaningful implications of words embrace the constituents of the linguistic and contextual paraphernalia of the speakers. In fact, speakers of a particular language are the ambassadors and mediators of evocative inferences which fluctuate from time to time and from context to context. Saeed (2009) supports the same idea that "lexical relations are central to how speakers construct meaning". (p. 54)

In this outlook, many scholars and researchers across the world contribute to lexico-semantic versions of their own varieties of English tinted by means of their usage intended for their cultural and communicative norms.

Aremu (2016) observed the emerging innovations in the new "hybrids" of the Lexico-Semantic Usages of Nigerian English with a particular emphasis on the language of the new media, students' sexual discourse, socio-cultural and family discourse, and the language of Nigerian political discourse. For this purpose, he administered questionnaires among 300 respondents randomly selected from three Nigerian tertiary institutes. The findings of his study show that dominant power of the press and new media, students' sexual discourse, outcomes of hip-up music, honorifics, cultural and lexical transfer, coinages, acronyms, abbronyms, analogy and lexical borrowing result in creative lexico-semantic Nigerian English practices.

Okongor (2015) focused on the distinguishing aspects of Lexico-Semantic Analysis of military language in Nigeria by means of oral interview and observation. His findings clearly indicate that the aspects of military language are quite dissimilar from those of other varieties of English and ultimately leave a deeper impact on their day-to-day lives.

Ehineni (2014) scrutinized the unusual linguistic and stylistic essentials in Nigerian English print media.In this regard, he gathered data from national Nigerian English newspapers and afterwards carried out the linguistic investigation in order to throw light on the classification of linguistic characteristics particularly in terms of lexical, structural and rhetorical features that are specific to Nigerian newspapers. The outcomes of the study further revealed that these features are stylistically diverse as compared to the English language employed for the official usage and which further marks a unique Nigerian essence in the language of the print media.

Moreover, Okunrinmeta (2014) looked at the Syntactic and Lexico-Semantic variations in Nigerian English, while drawing attention to the inferences and challenge in the ESL classroom.He explored a range of kinds by means of Exonormative model, predominantly with reference to Nigerian socio-cultural framework which demonstrated that Nigerian English marks the indication of local variations in Nigerian English. The findings of his study replicate that the Nigerian variety of English is flexible enough to encapsulate the social-cultural actualities of Nigeria. Also, Nigerian English is ripe enough to articulate a striking appeal for Nigerian students as compared to British and American versions of English which are inapt in handing over the Nigerian socio-cultural sensitivities.

Ekundayo (2013) highlighted Lexico-Semantic interference in Educated Nigerian English (ENE). In this context, he underlined redeployment of meanings, predominantly by means of semantic broadening and weakening in lexico-semantic dynamics of Nigerian Educated English (ENE).

Adebileje \& Araba (2012) examined the Lexico-Semantic Features in the native novel "The Joys of Motherhood" specifically with reference to Nigerian English Usage. The outcomes of their study emphasize that Igbo English is considered to be one of the ethnic varieties of Nigerian English in which lexical conventions mirror the Igbo culture and the English language. Also, this ethnic variety maintains the features of Igbo political and religious practice and attitudes, food and drinks, flora and fauna as well as societal facets of the Igbo natives.

Teilanyo (2010) while bringing to light Lexico-Semantic Nigerianisms in Nigerian Newspapers laid emphasis on linguistic plane of vocabulary and meaning. He argued that the lexico-semantic categories comprised of the occurrence of unEnglish words and expressions in Nigerian English contexts. He further scrutinized semantic extension, tautology, malapropism, code-mixing and innovative idiomatic expressions. His findings revealed that Nigerianisms are infact the indexical markers of Nigerian English and such indexical manifestations pave the way for further formalization, codification and elaboration of Nigerian English by means of a reliable source of newspapers.

In Pakisstani context, Rehman (2014) brought to light various lexical and semantic categories in general which further emphasized that words can be borrowed, translated, hybridized and even semantically changed. 
Furthermore, Mahboob (2009), a celebrated scholar discussed that the English language in Pakistan typifies "South Asian Islamic sensitivities".

Moreover, while referring to the Pakistanization of English, lexically permeated with the shade of the functional nativization, Baumgardner (1993) holds the view that in order "to be able to read a local Pakistani English Newspaper thoroughly and with complete understanding, it is necessary that the reader be familiar with both the Urdu language and Islamic culture." (p. 242) Thus, in reality, society marks the same way as predisposed by the affluent modes of reading while offering a nativizedcolor or even the code-mixed forms in indigenous background. Hence, socio-cultural factors chiefly concerning physical realities, family bondings, local coinages, ideological influences, political influences and even economic state of affairs along with diverse linguistic factors powerfully contribute to Pakistani variety of English. As Parhi (2008) asserts:

"In modern times, no particular subject is independent by itself. Registers from all disciplines jumble together and get validity through the register of journalism. The journalists...create a medium that can interest the variety of readers...The readers become the market for the product that is the newspaper..." (pp. 50-51)

Therefore, the present study is uniquely marked owing to the investigation of a corpus-based study of Lexico-Semantic variation in Pakistani English Newspapers, which, in its entirety, is unexplored in Pakistani milieu. The term "Pakistanism" is adapted here in correspondence with the terms "Americanism" and "Africanism" (Dalgish, 1982; Schmied, 1991). "Pakistanism" is characterized on the basis of the utilization of words and phrases woven within the thread of sentences, deeply entwined in discourse and pragmatic relations and strongly embedded within the culture and thought-processes of Pakistanis, particularly among those of rank and education. Such constructions are the distinguished versions explicably dissimilar in usage from those of British and Americans or due to borrowing, domestication and innovation processes. Moreover, the corpus-based approach supports in substantiating the data from the real life by the users of the language in changeable circumstances of Pakistani culture while underscoring its linguistic gamut interconnected to expanding spheres of life.

\section{Research Methodology}

\subsection{Framework of the Study}

This is a corpus-based study which takes into account the specialized corpus derived from the two leading Pakistani English Newspapers, i.e., Dawn and "The News" owing to the highest readership and significantly effective utilization of the text extracted from the real life. Pollach (2012) highlights the same when he asserts that the corpus-based study encompasses the authentic real life scenarios for the purpose of language development underpinning a text corpus describing both quantitative and qualitative text analysis observations. (p. 263)

\subsection{Research Design}

The corpus utilized for the present study consists of 15317950 words. In this regard, patterns of occurrence of lexico-semantic categories based on the general perceptions of context-dependent usage in Pakistani society are undertaken for further descriptive analysis in terms of qualitative version of data. As Talaat (2002) puts it that "Qualitative version of data allows comprehensive analysis of particular instances- whether individual instances or texts" (p. 35).

In this connection, Baker et al. (2008) is right in their emphasis on mingling corpus-based technique with qualitative scheme to categorize frequent and appropriate linguistic patterns as they supply "useful methodology synergy" (p. 223).

Furthermore, the present study covers Basic-Applied range which progresses greatly from "theoretical (Basic) to the very practical (Applied). At the basic end of the continuum, research is hypothetical, dealing mainly with highly abstract constructs." (Perry, 2005, p. 73)

Hence, both patterns and meanings genuinely intertwined within a text can be drawn out for a productive scrutiny. Talaat (2002) reinforces the same thought in these words:

"If the meaning of language lies in the patterns which different linguistic units make together in a given text, then its divergence may also lie in the way these units are used in a given text." (p. 36)

So, the present study is exclusively interwoven within the thread of corpus in order to study the lexico-semantic tendencies of Pakistani English in the Pakistani English Newspapers while underscoring the linguistic interpretations involved in it and which are utilized in a different way in Pakistani English newspapers. The study, therefore, addresses how lexico-semantic factors in cooperation with multiple contextual scenarios interrelate to 
be a precursor for change by means of structural and non-structural inferences. In this way, the English language in a non-native locale may be exercised as an effectual interactional tool which is dissimilar from the English language used in native settings. Consequently, the present study accentuates the social repercussion as well as structural and non-structural factors while associating these with lexical and semantic factors.

\section{Data Collection}

As the present study focuses on lexico-semantic features in Pakistani English Newspapers ("Dawn" \& "The News") so for the accomplishment of the objectives of the present study, newspapers and specifically the selected sections comprising of national news and the news from the four most important cities of Pakistan, i.e., Karachi, Lahore, Islamabad, Quetta, sports' news, top stories, opinions and editorials are considered for carrying out the analysis of the present study owing to the diversifying range of linguistic items and occurrence of "internal" modifications within a locally recognized norm. Newspapers are taken into account because they offer a firm foundation for a wide range of dissimilarities and variation. As Uzair, Mahmood, \& Raja (2012) rightly put it:

The language of English newspapers in Pakistan has fascinated a lot of linguists for having outstandingly observable dissimilarities from Standard English. (p. 122)

\subsection{Sampling for the Study}

For the present study, purposive sampling is employed for the collection of data which underlines the consideration that items from a pre-specified group are purposively sought out and sampled which further authenticates the inclusion of rich sources of data that can be exploited to generate or examine the explanatory frameworks (Gerrish, Lacey, \& Cormack, 2010, p. 149). In addition, the sample size for the extraction of data is measured keeping in view the usual length of the texts because complexity usually arises during the selection of the best sample size in such explanatory agendas where it fluctuates from constituent to constituent. The same observation is supported by Oostdijk (2001) when he is of the view that the sample sizes diverge from component to component; while it is unfeasible to detect what the optimal sample size is, methodical opinions are taken into account while reconciling on what in fact corresponds to an appropriate sample. In this context, the natural length of a text purposefully plays an important part (p. 107). In this way, selected samples become the "representatives" and validates the research. Therefore, the present study ensures the openness and natural lengths of selected newspaper texts.

\subsection{Compilation of the Corpus}

The corpus compilation for the present study is principally linked to combining all preferred texts in computer-readable format. For this reason the researcher gathered the data obtainable from web resources chiefly in the form of e-papers. For the accomplishment of research objectives, all the diagrams and tables are removed in order to well-match the software, i.e., Antconc 3.2.1w has been used for the present study. One foremost characteristic of Antconc 3.2.1w is that it can search for the key terms by means of utilizing accepted lexis. Likewise, it carries out a study of concordance lines encompassing the relative constructs from both left and right sides which lays foundation for the qualitative analysis in terms of contextual constructions extracted from KWIC (Key Word in Context) from several target texts. The context-dependent lexis has its roots in lexicosemantic constructs deeply delved in background information and evocative elucidations related to the texts and real-life setting.

Therefore, for the achievement of objectives, the present study addresses the gap by launching an association of lexico-semantic categories within the text extracted from a corpus based on Pakistani English Newspapers which is compiled to inspect the sociolinguistic perspectives. The study further accentuates the social implications as well as structural and non-structural aspects while correlating these with the dynamics of lexical and semantic features.

\section{Analysis and Discussion}

For extracting lexico-semantic variation from Pakistani English Newspapers, descriptive analysis was carried out in order to analyze the socio-cultural perceptions, while highlighting the "mind set" of Pakistanis accommodating communicative practices. The following lexico-semantic categories have been taken into for descriptive analysis:

\subsection{Coinages}

According to Yule (2010), Coinage is one of the word formation processes which refers to as "the totally new words". Also, the coinages are the "invented terms, but after their first coinage they tend to become everyday 
words in the language" (p. 54). Coinages are also described as neologisms which are particularly invented to provide accommodation to the speakers to augment intelligibility and also to support communication in typical socio-cultural milieu and are recognized by the speech community. The following examples of coinages highlight the lexico-semantic content in Pakistani perspective:

\section{$>$ Khan-i- Khanan of Chamchas}

This hybridized innovative phrase is very common in Pakistani usage owing to the addition of the word "chamchas" which has its roots in Pakistani politics whether it be the country politics or the domestic one. "Chamcha" owes special implications in Pakistani politics. A "Chamcha" is concerned with power and influence as moth is attracted towards flame. Also, the compound "khan-i-khanan" refers to one of the nine ministers in Akbar's court. But, in Pakistani political terms, this coined phrase is extensively employed to highlight the extremely typical practice and very plausible art of sycophancy or the "sweet talk" of the flatterers and particularly the political leaders/ministers who use the tacts to hail anyone of their choice as a deliverer in order to grab the selfish gains by merely "buttering up" in the garb of "false praise". Also, in domestic politics, it serves as having the same implications. Such phrases are coined out of utter inevitability while reflecting a locally "nativized" but unique tendency of innovation in Pakistani communicative practices. Moreover, its morphological building blocks which are combined to form complete phrase are connected to affixation process in general and infixation process in particular. The same phrase further emphasizes the utilization of Persian morpheme "-i-" in the formation of compound nouns which is reminiscent of the era of amalgamated Indian Muslim culture. On the whole, the term is derived from a warehouse of champion cutlery which is in fact a serious stuff used to draw attention towards the professionals' behaviour in Pakistan.

\section{$>$ Gullu Butts}

The coinage "Gullu Butts" is invented to revive the lamentably brutal history of "reign of terror" created in the form of carnage which took place at Minhaj-ul Quran in June, 2014 by a historically tarnished and aggressive protagonist Shahid Aziz alias "Gullu Butt" who, by means of his Maula Jutt's (representative of Punjabi ethos and psyche which is the sole mirror of Punjabi identity, i.e., human cockroaches, which are brutal and savage) gaze, got identification due to jailing and splitting an annoying motorbike that just won't start. As cited in a newspaper headline:

\section{The reign of Gullu Butts (Dawn, September 26, 2014)}

The newspaper headline also indicates that such innovative wordplays have a strong intelligible value owing to the prevailing conditions in Pakistani socio-cultural and political context. In this connection, Khan (2013) highlights the same idea that words are neologized in order to express the prevalent thoughts and state of affairs in the society but most notably owing to the non-availability of lexicon recapitulating the socio-cultural realities. (p. 7)

Thus, in this outlook, the term "Gullu Butt" gained recognition and endorsement in the Pakistani society as a socio-political phenomenon. It is interesting to note that the name "Gullu Butt" undergoes a semantic change in terms of "pejoration" with fluctuation of meaning from positive to negative; positive connotation in terms of a childhood name which was the product of love and tenderness of familial relationships chiefly by those who carve up the closest ties and negative connotation implies the change from positive nature of meaning to a negative character in the form of an automobile smasher having violent behaviour. Hence, adding up of plural marker "-s" while making it "Gullu Butts" marks the indication of this sweeping version of the generalized phenomenon rampant in Pakistan which also lends lexico-semantic change when it refers to the basis of instilling fear and fright within the peace-loving folks by means of the horrifyingly atrocious actions and horrible looks. So, it is evenly appropriate to all such characters in the society. For this reason, such coinages are difficult to construe when transplanted in alien cultures and are quite unique in the respective cultures.

\section{$>$ Lota Culture}

Another very prominent bilingual compound coinage consistently used in newspapers, in order to grasp the attention of the readers by means of prevailing ideologies, is "Lota Culture". "Lota" is originally made of brass, copper or plastic used for personal hygiene and is regarded as the integral item of sub-continental and Muslim culture, i.e., the globular vessel of everyday use. This compound coinage "lota culture" ironically highlights the performance of "lotas" (those who change their loyalties as a matter of principle while acting as turncoats, weathercocks) while marking the culture of notoriety. It is very grappling particularly when connected to Pakistani politics owing to its usage in terms of context. Such lexico-semantic innovations, after their first usage, won fame and recognition by the public due to their idiosyncratic character which, in due course, achieve a 
standardized version due to their relevance in Pakistani socio-political perspectives. In this regard, Uzair, Mahmood, \& Raja (2012) rightly assert that such coinages are strongly rooted in newspapers and consequently, the explicit language of newspapers genuinely intrudes in the language of readership (Uzair, Mahmood, \& Raja, 2012). For this reason, the lexico-semantic implication of this typical Pakistanism (the use of phrases or terms exclusive to Pakistani culture) implies final resort for the crooks and particularly the "political shuttle-cocks" whose ironical claims, falsely put, predominantly supporting national concerns, are contradictory in nature due to their habit of fluctuating allegiances which is in fact a characteristic feature of despicable culture of Pakistani politics. Due to this convention of usage in the omnipresent media, such ground-breaking realities are established and eventually given currency owing to their exploitation in mass media. Here, Kachru's concept of "Range" and "Depth" is applicable here; "range" in terms of expansion of English in the relevant social and cultural context and depth in terms of diffusion of English-knowing bilingualism to various societal altitudes.

\section{$>\quad$ The Sultan of Swing}

The coinage "the sultan of swing" is another new creation of Pakistani English Newspapers. "Sultan" basically refers to a Muslim sovereign having authority or power. This coinage "the sultan of swing" specifically points out towards the former Pakistani swing bowler who has an outstanding ability to swing the ball in both directions. In Pakistani context, this coinage heralds the exceptional performance of the legendary Pakistani left-hand pace man, i.e., Wasim Akram in the cricket history. He is one of the leading fast bowlers of all times who played a very important role in Pakistan's World Cup victory of 1992. Owing to his superb and wide-ranging skills in bowling, this former Pakistani captain is regarded as "the sultan of swing" who has an outstanding ability to burst through batting-line ups. He is also competent in moving the ball late both in the air and off the pitch with slight changes of pace, having one of the most diverse arsenals in cricket history, with inswing, outswing, yorkers, and bouncers being just some of the weapons at his disposal. Moreover, due to his awesome command of his overpowering use of reverse swing that it prompted accusations of ball-tampering. Such coinages play a leading role in emergence of a novel sequence of metaphorical language having contextual semantic feature. In the light of the aforementioned contextual factor, this coinage cannot be interpreted on the basis of "semantic transparency" due to its opaqueness. It further complements to the social interpretation added to it within Pakistani context.

\section{$>$ Cat-eyed tea seller}

Another captivating lexico-semantic Pakistanism (the use of phrases or terms exclusive to Pakistani culture) exclusively employed in media is "Cat-eyed tea-seller". This coinage refers to a person, particularly a tea seller with velvety blue, green eyes, who used to prepare and sell milk tea in the Pashtun (based on a Pakistani province, Khyber Pakhtun Khawah, hereafter, K.P.K.) market. This coinage is based on "Chai wala's gaze" (referring to the same tea merchant's captivating eyes) while bringing to light the story of a Pakistani tea-seller's entrancing, piercing and "dreamy" eyes who afterwards became an emblem of beauty while turning him out into a fashion icon. One of the newspaper's headline evidently demonstrates this reality as:

\section{A Pakistani chaiwala's gaze creates a window into the nation's soul [The National, October 20, 2016].}

Another newspaper depicts the same reality as:

“Cat-eyed” tea-seller sparks soul-searching [October 20, 2016].

This metaphorical coinage has socio-cultural implication deeply entrenched within the story of a bluegreen-eyed tea-seller who had set the internet alight from Pakistan to India and whose tempting eyes earned a good name for him in the glamour world. His visual rendering spread around the internet, sparked fervent debates on class, objectification and the place of ethnic Pashtuns in society. This coinage further draws attention to the story of lower classes turning from "rags-to-riches" which further sparks ardent arguments on the social aspects of class distinction and objectification in Pakistani society where women have long battled for their rights and hardly ever articulate their thoughts overtly, that zeal soon morphed into a powerful debate on what it meant to reduce a poor man to a stunning object. Such lexico-semantic variation distinguishly spots the demarcation of cultures as highlighted by Boas (1963) and viewed by Kruhm (2003):

“...the differences among cultures are result of cultural histories and a culture's values and norms resulted from that culture's unique history... a trait that makes sense in one culture may seem curious in another." (p. 23)

\section{$>$ Tan-inducing Sunlight}

This coinage has alternate phrases employed in cross-cultural communication like "sun tanning" or "brown from the exposure of the sun". The lexical uniqueness of this coinage lends metaphorical description and is also 
marked by semantic transparency. Such metaphorical elucidations provide room for creativity, originality and exceptionality. As, Parhi (2008) strengthens the same idea:

Being metaphorical in your thought and language structure means that one tends to develop one's own lingo, following one's own distinct style (p. 166).

The insinuation of the adjectival phrase manifestly points towards the tanning and the retentively darkening feature which is ascribed to sunlight due to the direct exposure to sun for long hours and which may result in pigmentation or blistering. Moreover, "tan-inducing sunlight" also refers to the sunlight of hottest regions of Pakistan which is a sun-drenched state where the negative effects of regular exposure to sunlight may result in darkening of skin and also leads towards skin problems. Hence, it can be emphasized that this coinage in the form of endocentric compound has lexico-semantic variation which can be extracted from its morphemic components.

\section{$>$ Open Court}

This is a lexical innovation particularly with reference to the socio-political and cultural set-up of Pakistan. The coinage "Open Court", alternatively utilized as "open justice" in World Englishes refers to a court that is officially organized by the judiciary and is declared open for the discharge of appropriate judicial procedures. In Pakistani context, it also refers to a court that does not hold back access of general public. This "open court" is further inferred as "Khuli Katchehri" primarily supervised by the Chief Minister and other higher officials at provincial and federal levels. The reason of ascertaining these "open courts" is to resolve the problems of the people within a very short period of time. In Pakistan and chiefly in the Punjab province, these open courts are established on the orders of C.M. Punjab in which the common folk file their complaints and afterwards able to get prompt redress of their grievances. It's like getting justice at their threshold. Thus, such coinages clearly reveal the idea of cultural relativism that the norms of the culture are chiefly derived from the shared attitudes, principles and patterns of behaviour.

\subsection{Idiomatic Collocations}

Collocations are referred to as co-occurring words which bring to light "the relationship a lexical item has with items that appear with greater than random probability in its (textual) context" (Men, 2017, p. 19).

Moreover, Smadja (1993) depicts the characteristics of collocations by asserting that they are arbitary, domain-independent, recurrent and cohesive lexical clusters. In this regard, patterns of collocations correspond to a variety of lexical entities ranging from fixed to free arrangements of lexical components. Following patterns of collocations are analyzed in Pakistani context which show that Pakistani users are competent enough to grasp them in their relative context:

\section{$>$ His Woman}

This collocation appears in the form of a Noun Phrase and can be regarded as a grammatical collocation but can only be inferred by means of contextual clues. It has its roots in the socio-cultural as well as the religious bonding because it demotes the woman who is legally linked toa man. Here, the legalized condition is valid as formulated by the religion and the Islamic culture which determines the legal bond of man and woman in terms of marital relationship i.e., husband and wife. Thus, this collocation has grounding within the cultural aspect based on Islamiazation. This feature is a reflection of Boas' notion that culture must be comprehended in terms of a thorough examination of religion, marriage customs, social taboos etc. (Boas, 1963).

So, this collocation also serves as an indicatorof comparative difference of cultures across the globe where the language functions to all intents and purposes and where understanding and comprehensibility are molded with in the local coloring of nativized norms.

\section{$>$ Loot sale}

This collocation seems unusual apparently due to its structural arrangement which is quite contrastive in its core. As "loot" is mainly related to "stealing" or "plundering" but here the repercussion is quite conflicting. It refers to the sale of items at unpredictably low rates which are fairly captivating for the purchasers in order to grab the items at the call of first come, first get. In addition, in Pakistani context, "loot sale" is also sarcastically connected to the blind sale of institutions for the accomplishment of one's egocentric motives. As it is obvious from the newspaper article:

Such has been the loot sale of Sindh land during recent years that even the office of the Senior Member Board of Revenue does not have any idea as to how much land has been allotted in the province during the last 10 to 15 years. (The News: September 13, 2015). 
Apart from this collocational existence, "loot sale" also undergoes a semantic transformation regarding the activity that is being carried out by Pakistanis within their own social and cultural structure. Semantic transformation occurs in the sense that it is correlated to the sale of items with minor sale prices and thus has its nearest equivalents like "amazing deals" or "hottest deals" which create a difference in World Englishes. Such conventions of usage replicates the idea of "acculturation" as well as "nativization" Also, it corresponds to the cross-over contributing to the cannons of creativity (Brown \& Ogilvie, 2009, p. 366). Hence, "loot sale" is extended beyond its collocational use in terms of semantic change with the cross-over of events in different cultures.

\section{$>$ Drag the name in the mud / Drag the good name through the mud}

The aforementioned example of collocation represents somewhat frozen nature of strings of words whose connotations do not reflect the nuances of their constituents (Benson et al., 1986, pp. 252-253). Such collocations are idiomatic in nature. It further highlights the metaphorical dimension as clear from the newspaper text:

"It was disappointing that people lied and tried to drag my name in the mud," he told AFP, without directly referring to the leaks (The Nation, May 20, 2016).

This idiomatic collocation emphasizes the metaphor "mud" which implies "stain", bring into disrepute and humiliation to one's personality. In this regard, "dragging one's name in the mud" entails to the things intentionally done that put some-one in ignominy and discredit. Such collocational patterns are acknowledged in Pakistani context owing to its usage in media. Here, Rehman (1995) is reasonable in representing that only such lexis remains resilient which are socially accredited and received by the users of the society.

\section{$>$ Reins of Power}

This idiomatic collocation is a generalization as it is not doable to hold the reins of an abstract idea, i.e. power. The configuration of the idiom evidently signifies that it is somewhat semantically transparent and that only a skilled person can grasp the reins of power and it can be well explained while keeping in view the socio-political set-up of Pakistan. Pakistani politicians and even the dictators are conscious of the horse trading in politics particularly when it comes to trading of votes or it is the matter of dishonesty and bargaining. It further entails the know-how of exploiting the power within and outside the political set-up. "Hold the reins" might serve as a n alternative in different cultures. Hence, its lexico-semantic innovation has its roots within the socio-political context of Pakistan which reverberates the diversifying undercurrents of lexical items instilled in typical Pakistani colour. Thus, the usage of this idiomatic collocation entails the use of English in "un-English" contexts and predominantly in response to the socio-political dynamics of Pakistan which echoes the nativized coloring in terms of Kachru's notion of "range".

\section{Son of the soil}

This idiomatic expression is not much predictable in its entirety rather the opaque elucidation adds a new but locally nativized flavour in it. Mackenzie (2014) states in this regard that "...the use of local idiomatic coinages is devised to meet an immediate communicative need" (p. 110). It refers to the native male of locality who is of the native origin. Also, it refers to the one who is not only successful but also holds an outstanding place in the society. Further, it explains the nationalistic character and the dedication which later proves to be significant owing to some exceptional accomplishment of the person and due to which he is hailed by his society. As presented in the newspaper text:

He regretted that even a person like Dr. Abdul Qadeer Khan is not being considered as "son of the soil" just because he too is a "Mohajir" (The News, July 10, 2015).

In different cultural practices, the phrase may implicate the person who works on a farm / land while taking up his father's occupation and also who is born in the same country. It is commonly employed in Pakistani English newspapers which draws some relationship with the cultural standpoint and which is also acceptable by the users of the community. Brown \& Ogilvie (2009) state in this regard that this correlation with the cultural stance heralds Kachru's conception of "functional nativeness" based on the creativity "used to construct localized identities" (p. 366).

Such localized identities pave the way for distinction at lexical and semantic levels. Here, Babatunde (2001) is right in emphasizing that the most prolific and vibrant mode of variation is the point of lexis. At this level, the speakers of the English language, particularly on the outer circle enable themselves to defy the conventions on hand, owing to the pragmatic grounds and thus having the flexibility to mould according to the new culture where the English language has been transplanted. (p. 109) 


\section{$>$ Can't clap with one hand}

Such collocations are regarded as arbitrary as well as having recurring associations between lexical components in some particular lexico-semantic and syntactic setting. They are idiomatic in nature and for this reason the word sense cannot be simply predicted owing to morpho-semantic opaqueness. Hence, "can't clap with one hand" cannot be interpreted in the literal sense due to its context-dependent nature. It means that certain things cannot be completed by one person unaided. It further asserts that the achievement of a common end cannot be made possible on one's own. This interpretation can be better understood in the light of this news:

YOU can't clap with one hand," one of the rapists in the notorious Delhi gang rape casehad famously said after being convicted of rape and murder. (Dawn, May 10, 2017).

Therefore, this lexico-semantic Pakistanism confirms Moag's (1992) developmental phases when he discusses the "life cycle of non-native Englishes". According to him, such patterns in non-native Englishes are a blend of linguistic and distinctively cultural implications of the local users and thus afterwards, accommodated in their relevant environments. Moreover, the such idiomatic collocations are accepted by the local users owing to the relevant contextual constructs in functional scenarios. Thus, the lexical constituents are not apparently connected to each other rather the communicative undertones determine the real functional value.

\section{Talking Terms}

Another lexico-semantic uniqueness prominent in Pakistani English is "Talking terms". This collocation pattern is based on distinctive co-occurrence of a pair of lexical items. It is idiomatic in nature but unlike pure idioms which are transitional in nature, such arbitrary recurrent word combinations can be presumed from the meanings of their components (Brinton, 1999, p. 8). He further explains that collocations do not always conform to the traditional patterns, rather they occur in extended terms at times owing to communicative competence and needs of the users. In this regard, "Talking terms" in fact conveys the sense of refusal when someone is not willing to speak/converse especially in a state of anger/contradiction. This implication highlights the negative tendency regarding usage of the phrase. As represented in a Pakistani newspaper:

\section{PPP ministers and Shahbaz not on talking terms (Dawn: September 15, 2008)}

This newspaper headline further confirms Kachru's concept of "Range" particularly in terms of social context where the lexical items are revolutionized in functional contexts which are user-friendly and hence are better comprehended by the users of the language. Kachru (1985) is right in asserting that:

English has an unrestricted functional range in diverse of social, educational, administrative, and literary globes. It also has added gigantic depth regarding users at different levels of society. Accordingly, there are significant characteristics within such institutionalized varieties. (Kachru, 1985, p. 13)

\section{$>$ Tall Claims}

This lexical collocation pattern occurs recurrently in Pakistani English but at the same time it also appears as the idiomatic expression which is relatively frozen as compared to the ordinary string of words. It is widely used in Pakistani media particularly highlighting the practices of Pakistani politicians. The adjectival phrase "Tall claims" highlight the hyperbolic adaptation of the elevated and pompously hollow claims of Pakistani politicians which only subsist in words and not in deeds. Such claims tempt the people to enmesh themselves into the spider's web of services. As highlighted in the headline:

\section{Sit-ins galore and tall claims (February 16, 2013)}

Therefore, the collocation testifies Kachru's conception of "functional nativeness" which chiefly highlights the "range" and "depth" of Pakistani users and mainly the journalists and columnists towards such "attitude-specifying tags" in terms of realization of sky high assertions. Hence, this lexico-semantic Pakistanism is accepted and recognized by Pakistani society where the handling of such lexis epitomize the socio-political practices and are conveniently construed within the related context.

Thus, the aforementioned analysis highlight that the frequent utilization of such expressions in culture-specific as well as functional settings along with the nativized texture in Pakistani English Written Discourse lays concrete foundation for formalization, codification and augmented justification of the communicative purpose of Pakistani English. Therefore, Pakistani English Written Discourse justly corresponds to the dynamic linguistic novelty as well as the suitable and reliable source for the codification of Pakistani English.

\section{Conclusion}

The purpose of the present study was to identify and analyze the two major lexicosemantic categories i.e., 
coinages and idiomatic collocations by means of corpus based data chiefly from Pakistani English Newspapers. In the light of the findings, it can be maintained that these core lexico-semantic categories entail an elevated degree of traditionalism and behavioral prototypes in the choice of constituent lexicalentities. It is the lexico-semantic comprehension that proves to be a strong determinant aspect in bringing to light the significant application of coinages and idiomatic expressions in non-native context of Pakistani culture which can captivatingly grasped by the local people in their pertinent background. Hence, such expressions are recurrently resilient in Pakistani socio-cultural context and have achieved the status of institutionalized phrases within the non-native mould of Pakistani English which evidently specify that the English language in Pakistan has blended itself within the socio-cultural shades which are ultimately the product of the unique forms which are genuinelyim planted in our own ways of life as highlighted in Boas' theory of Cultural Relativism (1963) and Kachru's concepts of "Nativization" and "Acculturation" (1992). Thus, the amalgamization of Pakistanization in the English language is something that really counts. This evolution is still in progress as a promising means in various fields while highlighting the diverse progression of possibility of expressions for multicultural and multilingual users. So, in this association, it can strongly be affirmed that English is no more the possession of one country; rather this transplanted language within the non-native contexts has the suppleness for adaptations within the transplanted culture even. So, in this outlook, British English is not the only homogeneously standardized and norm-providing variety, on the basis of which other varieties are to be evaluated, rather every individual non-native society sets its own standards and norms deeply rooted within the indigenous cultural molds.

Hence, in Pakistani context, the present study ascertains a call for codification of these lexico-semantic expressions in books and dictionary of Pakistani English. It will further be a motivational source to bring together and extend the written corpus of Pakistani English which may further open new vistas of knowledge in terms of employment of corpora for systematic classification of other lexico-semantic categories like proverbs, metaphors, similes and their comparison with different corpora like British National Corpus (BNC) in broader spectrum. In addition, it also opens new avenues for the future researchers in terms of stylistic investigation by means of corpus-based methodologies based on the works of different writers in terms of national and even transnational perspectives. Also, it will expand the range of researchers because it mirrors the plausible adaptations in the English language by putting it on the pattern of linguistically prolific socio-cultural framework of Pakistani context. Findings of the study further reveal that such linguistic expressions are carved on the basis of inclinations which ultimately create a sense of empowerment.

\section{References}

Adebileje, A., \& Araba, O. (2012). Nigerian English Usage: Its Lexico-semantic Features. Language in India, 12(7), 1-27.

Aremu, M. A. (2016). Emerging innovations in the new "hybrids" of the lexico-semantic. The Internet Journal Language, Culture and Society, (42), 91-101.

Babatunde, S. T. (2002). World Englishes and the Paradox of English Language Teaching in Nigeria. S. T. Babatunde \& D. Adeyanju (Eds.). Ilorin: Haytee Press.

Baker, P., \& Khosravinik, C. et al. (2008). A Useful Methodological Synergy? Combining Critical Discourse Analysis and Corpus Linguistics to Examine Discourses of Refugees and Asylum Seekers in the U.K. Press. Discourse and Society, 19(3), 273-306. https://doi.org/10.1177/0957926508088962

Balasubramanian, C. (2016). How Indian is Indian English?: Indian Words in Register of Indian English. Asiatic, 10(2), 89-110.

Bangbose, A., Banjo, A., \& Thomas, A. (1995). New Englishes: A West African Perspective of Ibadan. Nigeria: Mosuo.

Baumgardner, R. J. (1987). Utilizing Pakistani newspaper English to teach grammar. World Englishes, 6(3), 241-252. https://doi.org/10.1111/j.1467-971X.1987.tb00204.x

Baumgardner, R. J. (1993). The English language in Pakistan. Karachi; Oxford: Oxford University Press.

Benson, M., Evelyn, B., \& Ilson, R. (1986). Lexicographic Description of English. Philadelphia: John Benjamins Punblications. https://doi.org/10.1075/slcs.14

Boas, F. (1963). The Mind of Primitive Man. New York: Collier Books.

Brown, K., \& Ogilvie, S. (2009). Concise Encyclopedia of Languages of the World (1st ed.). Oxford, U.K.: Elseview Ltd. 
Dalgish, M. (1982). A Dictionary of Africanisms: Contributions of Sub-Saharan Africa to the English Language. London: Greenwood Press.

Dustoor, P. E. (1968). The World of Words. New York: Asia Publishing House.

Ehineni, T. O. (2014). Lexical, Structural and Rhetorical Features of Nigerian. Journal of Arts \& Humanities, 26-32.

Ethnologue. (2017). Languages of the world. Retrieved from http:/Ethnologue.com/Language/Eng

Gerrish, K., Lacey, A., \& Cormack, D. (2010). The Research Process in Nursing (6th ed.). U.K.: Blackwell.

Kachru, B. (1965). The Indianness in English Language.

Kachru, B. (1985). Standards, Codifications and Sociolinguistic Realism: The English Language in the Outer Circle. Cambridge: Cambridge University Press.

Kachru, B. (1986). The Alchemy of English: The Spread, Functions, and Models of Non-native Englishes. USA: Pergamon Press.

Kachru, B. B., Kachru, Y., \& Nelson, C. L. (2006). The handbook of world Englishes. Malden, Mass; Oxford: Blackwell.

Khan, M. (2013). Neologisms in Urdu: A Linguistic Investigation of Urdu Media. Language in India, 13.

Laurel, J., \& Brinton, A. (1999). Collocational and Idiomatic Aspects of Composite Predicates in the History (p. 47). Amsterdam: John Benjamins Publishing Company.

Leech, G. (1974). Semantics. England: Penguin Books Ltd. Oxford: Oxford University Press.

Mackenzie, I. (2014). English as a Lingua Franca: Theorizing and Teaching English. U.S.A. \& Canada: Routledge.

McArthur, T. (1993). The English Language or the English Languages? In D. Crystal \& W. F. Bolton (Eds.). London: Penguin.

Men, H. (2017). Vocabulary Increase and Collocation Learning A Corpus-Based Cross Sectional Study of Chinese Learners of English. China: Springer.

Okongor, T. A. (2015). A Lexico- Semantic Analysis of Military Language. International Journal of Hum anities and Cultural Studies, 2(3), 652-664.

Okunrinmeta, U. (2014). Syntactic and Lexico-Semantic Variations in Nigerian English: Implications and Challenges in the ESL Classroom. Open Journal of Modern Linguistics, 4(2), $317-331$. https://doi.org/10.4236/ojml.2014.42026

Ostdijk, N. (2000). The Spoken Dutch Corpus: Overview and First Evaluation. Language and Computers, 36(1), 105-112.

Paikeday, T. M. (1985). The Native Speaker is Dead! New York: Paikedey Publishing Inc.

Parhi, A. (2008). Indian English Through Newspapers (1st ed.). New Delhi: Concept Publication Company.

Perry, F. L. (2005). Research in Applied Linguistics: Becoming a Discerning Consumer. Mahwah: NJ: Erlbaum.

Pollach, T. (2012). Taming Textual Data: The Contribution of Corpus Linguistics to Computer-Aided Text Analysis. Organizational Research Methods, 15(2), 263-287. https://doi.org/10.1177/1094428111417451

Rahman, T. (2014). Pakistani English. Islamabad: National Institute of Pakistan Studies.

Raja, R. (1938). Kanthapura (pp. 9-10).

Rosa, H. (1996). Cultural Relativism and Social Criticism from a Taylorian Perspective. Constellations: An International Journal of Critical and Democratic Theory, 3(1), 39-51. https://doi.org/10.1111/j.1467-8675.1996.tb00042.x

Saeed, J. I. (2009). Semantics (3rd ed.). London, U.K.: Wiley-Blackwell.

Schmied, J. (1991). English in Africa. London: Longman.

Strevens, P. (1992). English as an International Language: Directions in the 1990s (In B. B. Kachru, Ed.). Chicago: University of Illinois Press.

Talaat, M. (2002). Form and functions of English in Pakistan. Ph.d Thesis, The Department of English literature, Bahauddin Zakaria University, Multan, Pakistan. 
Teilanyo, D. (2010). Lexico-Semantic Nigerianisms in Nigerian Newspapers. Calabar Studies in Languages, $16(1), 21-49$.

Ulmann, S. (1962). Semantics: An Introduction to the Science of Meaning. Oxford: Blackwell.

Uzair, M., Mahmood, A., \& Khan, U. (2012). Impact of Lexical Deviations in Pakistani English Newspapers on the Language of their Readers: A Gender-Wise Analysis. International Journal of Business and Social Science, 3(5), 181-186.

Uzair, M., Mahmood, A., \& Raja, A. (2012). Role of Pakistani English Newspapers in Promoting Lexical Innovations. International Journal of Physical and Social Sciences, 2(6), 121-138.

Yule, G. (2010). The study of language (4th ed., pp. 53-54). Cambridge: Cambridge University Press. https://doi.org/10.1017/CBO9780511757754

\section{Copyrights}

Copyright for this article is retained by the author(s), with first publication rights granted to the journal.

This is an open-access article distributed under the terms and conditions of the Creative Commons Attribution license (http://creativecommons.org/licenses/by/4.0/). 